\title{
Body, space, and pain
}

\author{
Jörg Trojan ${ }^{1,2}$ *, Martin Diers ${ }^{2}$, Camila Valenzuela-Moguillansky ${ }^{3}$ and Diana M. E. Torta ${ }^{4}$ \\ 1 Department of Psychology, University of Koblenz-Landau, Landau, Germany \\ ${ }^{2}$ Department of Cognitive and Clinical Neuroscience, Central Institute of Mental Health, Medical Faculty Mannheim / Heidelberg University, Mannheim, Germany \\ ${ }^{3}$ Institute of Complex Systems of Valparaíso, Valparaíso, Chile \\ ${ }^{4}$ Department of Psychology, University of Turin, Turin, Italy \\ *Correspondence: trojan@uni-landau.de \\ Edited and reviewed by: \\ Hauke R. Heekeren, Freie Universität Berlin, Germany
}

Keywords: body perception, pain, psychology, neuroscience, spatial attention

\section{THEORETICAL BACKGROUND}

Chronic pain is accompanied by a variety of alterations in body perception. Pain patients often exhibit distortions in the perception of limb positions and sizes: back pain patients have problems in delineating the outline of their backs and their body image is distorted in the painful area (Moseley, 2008). Patients with Complex Regional Pain Syndrome (CRPS) suffer from intense pain in their affected hand and often perceive it as being larger than it actually is (Moseley, 2005). Amputees often report pain in their amputated limb and the amount of pain seems to be related to distorted spatial perception of the limb (Grüsser et al., 2001). Results from CRPS patients show that not only the perception of the body is affected, but that pain leads to a distorted perception of the peripersonal space surrounding the body (Reinersmann et al., 2011). At a more fundamental level, sensory changes associated with chronic pain states cannot be explained by peripheral deficits alone, rather, cortical representations seem to be involved as well.

Research on how body perception and pain are linked to each other has been conducted from different and possibly overlapping perspectives. One line of research highlights the importance of attentional biases toward or away from the location of pain. Another approach underlines the role of multisensory representation of our body and the surrounding space in the perception of pain and nociceptive stimuli. Extending this latter view, there is also work focusing in particular on the complex interplay between motor action and pain perception.

Experimental studies on the relationship between body perception and pain are contributing to our understanding of clinical findings and the development of new treatment approaches: nociceptive stimuli draw attention to their locations (Van Damme et al., 2007) and pain stimuli are perceived as less intense if attention is drawn away from their location (Van Ryckeghem et al., 2011). Vision of stimulated body parts reduces pain perception (Longo et al., 2009; Diers et al., 2013) and the larger the perceived size of a limb, the stronger is the effect (Mancini et al., 2011). Ongoing nociceptive input alters somatosensory localization (Trojan et al., 2009) and conflicts between frames of reference onto which somatosensory stimuli are localized modulate the perception of the stimuli (Gallace et al., 2011; Torta et al., 2013). Studies about the relationship between somatosensory inputs and motor planning suggest that visual-motor feedback leads to "peculiar" (and sometimes painful) sensations (McCabe et al., 2005).

\section{OVERVIEW OF THE ARTICLES IN THIS RESEARCH TOPIC}

In this Research Topic, three studies focused on the effect of painful or nociceptive stimulation on body representation and postural control. Bouffard et al. (2013) applied pain to the right arms of healthy participants and observed that the subjective body midline shifted to the right; non-painful vibration applied to the left arm also led to a right-shift. The pain-specific shift toward the stimulated side might be functionally beneficial to protect the painful area of the body. Steenbergen and collaborators assessed the agreement of spatial perceptual maps for touch and nociception and proposed that a common internal body representation can underlie spatial perception of touch and nociception (Steenbergen et al., 2012). Lelard and collaborators showed that imagining being in a painful situation induces changes in postural control and leg muscle activation, thus resulting in an increased stiffness compared to non-painful situations (Lelard et al., 2013). Anelli and colleagues did not study the effect of pain directly but explored the effect that potentially dangerous approaching stimuli have on motor responses: static neutral objects triggered faster responses compared to static dangerous ones (Anelli et al., 2013). Responses to dynamic objects were instead affected by the direction of the movement of the object.

Two studies addressed the question of how changes in body representations affect pain processing. In a virtual reality study, Martini and colleagues demonstrated that pain thresholds could be top-down modulated by changing the color of a seen arm (Martini et al., 2013). Pia and collaborators showed that right-brain damaged patients could feel pain in response to a stimulus produced in a foreign arm that was subjectively experienced as their own (Pia et al., 2013).

The interplay between movement, sensory feedback, and pain was specifically addressed by two studies. Foell and collaborators used a mirror setup in order to clarify the impact of sensory motor incongruence on pain perception (Foell et al., 2013). The results revealed that sensorimotor conflict affected perceived body integrity but was not sufficient to trigger substantial pain experiences in healthy volunteers. Meulders and colleagues induced pain-related fear of movements in healthy participants and demonstrated that this fear could be generalized to similar movements (Meulders et al., 2013). These findings may yield a better understanding of the role of fear and avoidance in chronic musculoskeletal pain. 
Four studies were conducted on clinical populations. Preißler et al. (2013) looked for the influence of prosthesis use in upper limb amputees on phantom limb pain and cortical thickness and suggested a relationship between prosthesis use and cortical plasticity of the visual stream. This plasticity might present a brain adaptation process to new movements and coordination patterns needed to guide an artificial hand. Riquelme and colleagues showed that administration of a somatosensory therapy could reduce pressure pain sensitivity in adults with cerebral palsy, without affecting other abilities such as texture recognition or tactile sensitivity (Riquelme et al., 2013). Turton and colleagues presented a new method to report body perception disturbances, targeted at patients with CRPS (Turton et al., 2013). Patients could manipulate a variety of features of an avatar on a computer screen, yielding 3-D representations of their symptoms. Wallwork and colleagues aimed at dissociating the ability to judge the rotation of the neck as compared to the rotation of the hand in dizzy people and observed that those patients show generally slower responses independently of to the task (Wallwork et al., 2013).

Finally, broadening the focus to social neurosciences, Krahé and collaborators proposed three factors playing a major role in pain perception: (1) the relationship between the person in pain and the social partner; (2) the possibility of the person in pain to understand the social partner's intentions; and (3) the degree to which the person in pain sees the social partner's possibility to act (Krahé et al., 2013).

\section{CONCLUSION}

The findings presented here demonstrate that the subjective experience of pain can only be understood in a larger framework of body representations and peripersonal space. The relationship between pain and these spatial representations is bidirectional, but the underlying neurophysiological mechanisms are not yet known. Regardless of this present lack of knowledge, the results reported in this Research Topic clearly bear clinical significance: future pain diagnostics and treatment approaches will benefit from putting more stress on body perception.

\section{REFERENCES}

Anelli, F., Nicoletti, R., Bolzani, R., and Borghi, A. M. (2013). Keep away from danger: dangerous objects in dynamic and static situations. Front. Hum. Neurosci. 7:344. doi:10.3389/fnhum.2013.00344

Bouffard, J., Gagné, M., and Mercier, C. (2013). Effect of painful and non-painful sensorimotor manipulations on subjective body midline. Front. Hum. Neurosci. 7:77. doi:10.3389/fnhum.2013.00077

Diers, M., Zieglgänsberger, W., Trojan, J., Drevensek, A. M., Erhardt-Raum, G., and Flor, H. (2013). Site-specific visual feedback reduces pain perception. Pain 154, 890-896. doi:10.1016/j.pain.2013.02.022

Foell, J., Bekrater-Bodmann, R., McCabe, C. S., and Flor, H. (2013). Sensorimotor incongruence and body perception: an experimental investigation. Front. Hum. Neurosci. 7:310. doi:10.3389/fnhum.2013.00310

Gallace, A., Torta, D. M. E., Moseley, G. L., and Iannetti, G. D. (2011). The analgesic effect of crossing the arms. Pain 152, 1418-1423. doi:10.1016/j.pain.2011.02.029

Grüsser, S., Winter, C., Mühlnickel, W., Denke, C., Karl, A., Villringer, K., et al. (2001). The relationship of perceptual phenomena and cortical reorganization in upper extremity amputees. Neuroscience 102, 263-272. doi:10.1016/S03064522(00)00491-7
Krahé, C., Springer, A., Weinman, J. A., and Fotopoulou, A. (2013). The social modulation of pain: others as predictive signals of salience - a systematic review. Front. Hum. Neurosci. 7:386. doi:10.3389/fnhum.2013.00386

Lelard, T., Montalan, B., Morel, M. F., Krystkowiak, P., Ahmaidi, S., Godefroy, O., et al. (2013). Postural correlates with painful situations. Front. Hum. Neurosci. 7:4. doi:10.3389/fnhum.2013.00004

Longo, M. R., Betti, V., Aglioti, S. M., and Haggard, P. (2009). Visually induced analgesia: seeing the body reduces pain. J. Neurosci. 29, 12125-12130. doi:10.1523/ JNEUROSCI.3072-09.2009

Mancini, F., Longo, M. R., Kammers, M. P. M., and Haggard, P. (2011). Visual distortion of body size modulates pain perception. Psychol. Sci. 22, 325-330. doi:10.1177/0956797611398496

Martini, M., Perez-Marcos, D., and Sanchez-Vives, M. V. (2013). What color is my arm? Changes in skin color of an embodied virtual arm modulates pain threshold. Front. Hum. Neurosci. 7:438. doi:10.3389/fnhum.2013.00438

McCabe, C. S., Haigh, R. C., Halligan, P. W., and Blake, D. R. (2005). Simulating sensory-motor incongruence in healthy volunteers: implications for a cortical model of pain. Rheumatology 44, 509-516. doi:10.1093/rheumatology/ keh529

Meulders, A., Vandebroek, N., Vervliet, B., and Vlaeyen, J. W. S. (2013). Generalization gradients in cued and contextual pain-related fear: an experimental study in healthy participants. Front. Hum. Neurosci. 7:345. doi:10.3389/fnhum.2013. 00345

Moseley, G. L. (2005). Distorted body image in complex regional pain syndrome. Neurology 65, 773. doi:10.1212/01.wnl.0000174515.07205.11

Moseley, G. L. (2008). I can't find it! Distorted body image and tactile dysfunction in patients with chronic back pain. Pain 140, 239-243. doi:10.1016/j.pain.2008. 08.001

Pia, L., Garbarini, F., Fossataro, C., Fornia, L., and Berti, A. (2013). Pain and body awareness: evidence from brain-damaged patients with delusional body ownership. Front. Hum. Neurosci. 7:298. doi:10.3389/fnhum.2013.00298

Preißler, S., Dietrich, C., Blume, K. R., Hofmann, G. O., Miltner, W. H. R., and Weiss, T. (2013). Plasticity in the visual system is associated with prosthesis use in phantom limb pain. Front. Hum. Neurosci. 7:311. doi:10.3389/fnhum.2013.00311

Reinersmann, A., Landwehrt, J., Krumova, E. K., Ocklenburg, S., Güntürkün, O., and Maier, C. (2011). Impaired spatial body representation in complex regional pain syndrome type 1 (CRPS I). Pain 153, 2174-2181. doi:10.1016/j.pain.2012.05.025

Riquelme, I., Zamorano, A., and Montoya, P. (2013). Reduction of pain sensitivity after somatosensory therapy in adults with cerebral palsy. Front. Hum. Neurosci. 7:276. doi:10.3389/fnhum.2013.00276

Steenbergen, P., Buitenweg, J. R., Trojan, J., Klaassen, B., and Veltink, P. H. (2012). Subject-level differences in reported locations of cutaneous tactile and nociceptive stimuli. Front. Hum. Neurosci. 6:325. doi:10.3389/fnhum.2012.00325

Torta, D. M., Diano, M., Costa, T., Gallace, A., Duca, S., Geminiani, G. C., et al. (2013). Crossing the line of pain: fMRI correlates of crossed-hands analgesia. J. Pain 14, 957-965. doi:10.1016/j.jpain.2013.03.009

Trojan, J., Kleinböhl, D., Stolle, A. M., Andersen, O. K., Hölzl, R., and Arendt-Nielsen, L. (2009). Independent psychophysical measurement of experimental modulations in the somatotopy of cutaneous heat-pain stimuli. Somatosensory Motor Res. 26, 11-17. doi:10.1080/08990220902813491

Turton, A. J., Palmer, M., Grieve, S., Moss, T. P., Lewis, J., and McCabe, C. S. (2013). Evaluation of a prototype tool for communicating body perception disturbances in complex regional pain syndrome. Front. Hum. Neurosci. 7:517. doi:10.3389/fnhum.2013.00517

Van Damme, S., Crombez, G., and Lorenz, J. (2007). Pain draws visual attention to its location: experimental evidence for a threat-related bias. J. Pain 8, 976-982. doi:10.1016/j.jpain.2007.07.005

Van Ryckeghem, D. M. L., Van Damme, S., Crombez, G., Eccleston, C., Verhoeven, K., and Legrain, V. (2011). The role of spatial attention in attentional control over pain: an experimental investigation. Exp. Brain Res. 208, 269-275. doi:10.1007/s00221-010-2477-y

Wallwork, S. B., Butler, D. S., and Moseley, G. L. (2013). Dizzy people perform no worse at a motor imagery task requiring whole body mental rotation; a case-control comparison. Front. Hum. Neurosci. 7:258. doi:10.3389/fnhum.2013. 00258 
Conflict of Interest Statement: The authors declare that the research was conducted in the absence of any commercial or financial relationships that could be construed as a potential conflict of interest.

Received: 20 December 2013; accepted: 13 May 2014; published online: 28 May 2014. Citation: Trojan J, Diers M, Valenzuela-Moguillansky C and Torta DME (2014) Body, space, and pain. Front. Hum. Neurosci. 8:369. doi: 10.3389/fnhum.2014.00369
This article was submitted to the journal Frontiers in Human Neuroscience. Copyright (C) 2014 Trojan, Diers, Valenzuela-Moguillansky and Torta. This is an openaccess article distributed under the terms of the Creative Commons Attribution License (CC BY). The use, distribution or reproduction in other forums is permitted, provided the original author(s) or licensor are credited and that the original publication in this journal is cited, in accordance with accepted academic practice. No use, distribution or reproduction is permitted which does not comply with these terms. 